\title{
Preface: 10th Brazilian meeting on adsorption
}

\author{
Igor Tadeu Lazzarotto Bresolin · Marisa Masumi Beppu
}

Published online: 2 December 2014

(c) Springer Science+Business Media New York 2014

In 2014, Brazil held the FIFA World $\mathrm{Cup}^{\mathrm{TM}}$, which was the most evidenced event in the worldwide community. However, we were also proud to host some other meetings that is boosting Brazil into a world class scientific production. Two months earlier, the Brazilian adsorption community promoted the 10th Brazilian Meeting on Adsorption (EBA10), the most expressive national conference in the field. This edition was chaired by Federal University of São Paulo (UNIFESP) Diadema, held from April 27th to 30th, in Guarujá, São Paulo. Reaching its tenth edition, EBA has experienced a growing interest by Brazilian and international scientific and business community.

To understand this growing, we need to know a little bit of history: the first EBA happened in Fortaleza, Ceará on June 1996, organized by an initiative of a group of professors at the Federal University of Ceará, led by Célio Loureiro Cavalcante Jr, PhD. This first meeting showed that the initiative was timely, not only because it relied on the presence of Prof. Douglas Morris Ruthven, PhD, but also by the number of participants (about 100) and quality of the 65 papers presented.

After six editions more (Table 1), EBA's growth came along breaking the country's frontiers. For this reason, the city of Campina Grande/PB received the EBA7 on June 2008, in which the 1st South American Symposium on Adsorption, Science and Technology and the 1st South

I. T. L. Bresolin ( $₫)$

Department of Exact and Earth Sciences, Federal University of São Paulo (UNIFESP), Diadema, SP 09972-270, Brazil e-mail: igor.bresolin@gmail.com

M. M. Beppu

School of Chemical Engineering, University of Campinas (UNICAMP), Campinas, SP 13083-970, Brazil
American School on Adsorption were held in parallel. The 9th edition, in Recife/PE, held the 1st Ibero-American Symposium on Adsorption (IBA1), which was a longstanding demand of many researchers on Adsorption area who met sporadically at conferences like the Fundamentals of Adsorption (FOA). The simultaneous occurrence of events led to a massive participation of researchers from the Ibero-Latin American region. In this meeting, it was decided that the IBAs will be held every three years. Prof. Juan Carlos Moreno-Piraján, PhD, from Universidad de los Andes (Colombia) is the chairman of IBA2, which will be held from 26th to 30th April, 2015, in Cartagena de Indias-a World Cultural Heritage by UNESCO.

This growth trend that EBA experienced was the driving force that motivated a group of young professors from the Chemical Engineering undergraduate program at UNIFESP to accept the invitation to organize the EBA10. The Enseada Beach in Guarujá, a beautiful coastal city $90 \mathrm{~km}$ far from São Paulo was chosen as the place to host this milestone tenth edition.

The development of human resources and the interest of undergraduate and graduate students were highlighted by carrying out the School of Adsorption during EBA10. As its name implies, in the school lessons on various areas of adsorption are taught by professors from educational and research institutions and companies. International invited speakers were responsible for five plenary lectures. Nine keynotes also took place held by international and Brazilian researchers, from academia and business community in order to foster research partnerships. Distributed in eight oral sessions and two poster sessions, 228 papers were presented. The conference was attended by 334 participants from Brazil, South America and Europe.

We thank our invited speakers (Gino Baron, Alois Jungbauer, Alírio Rodrigues, Abdelhamid Sayari, Juan Carlos 
Table 1 EBA's history

\begin{tabular}{llll}
\hline$\#$ & Year & Organization & City \\
\hline 1st & 1996 & Federal University of Ceará & Fortaleza/CE \\
2nd & 1998 & Federal University of Santa Catarina & Florianópolis/SC \\
3rd & 2000 & Federal University of Pernambuco & Recife/PE \\
4th & 2002 & Federal Rural University of Rio de Janeiro & Rio de Janeiro/RJ \\
5 th & 2004 & Federal University of Rio Grande do Norte & Natal/RN \\
6th & 2006 & State University of Maringá & Maringá/PR \\
7 th & 2008 & Federal University of Campina Grande & Campina Grande/PB \\
8th & 2010 & University of Campina and State University of Maringá & Foz do Iguaçu/PR \\
9th & 2012 & Federal University of Pernambuco and Federal University of Ceará - (IBA1) & Recife/PE \\
10th & 2014 & Federal University of São Paulo & Guarujá/SP \\
\hline
\end{tabular}

Moreno-Piraján, Diego Mantovani, Joaquín Silvestre-Albero, Eduardo Falabella Sousa-Aguiar, Marco Aurélio Cremasco, César Costapinto Santana, Moisés Bastos Neto, Cyril Leenhard, Carlos Andrés Donado, Guilherme Toledo and Darren Broom), financial agencies (FAPESP, CNPq, CAPES), sponsors, all participants, and our colleagues on the organizing and scientific committees, for their contributions to the success of the conference.

This issue and also the November 2014 issue of Adsorption collect selected manuscripts presented at EBA10 that have been accepted after the peer-review process with the usual quality standards of the journal, covering various aspects of Adsorption. Ranging from application in petroleum systems, passing through gas separation, environmental, thermodynamics, and including biotechnological molecule separations, these manuscripts give the taste of the diversity and depth of research developed in South America and shown at EBA. We wish to express our gratitude to all the authors for their contributions, the referees for their invaluable assistance, and Prof. Gino Baron, $\mathrm{PhD}$ for the opportunity to include these papers in Adsorption Special Issues.

Finally, we invite all scientific community to participate in IBA2 in Cartagena de Indias, Colombia in April, 2015 and in EBA11 in Aracaju, Sergipe, from 22nd to 27th April 2016. 